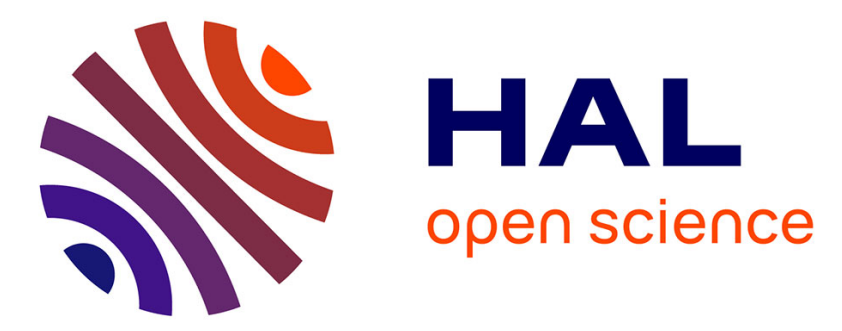

\title{
Anaerobic digester bioaugmentation influences quasi steady state performance and microbial community
}

Kaushik Venkiteshwaran, Kim Milferstedt, Jérôme Hamelin, D. H. Zitomer

\section{To cite this version:}

Kaushik Venkiteshwaran, Kim Milferstedt, Jérôme Hamelin, D. H. Zitomer. Anaerobic digester bioaugmentation influences quasi steady state performance and microbial community. Water Research, 2016, 104, pp.128-136. 10.1016/j.watres.2016.08.012 . hal-01608636

\section{HAL Id: hal-01608636 \\ https://hal.science/hal-01608636}

Submitted on 27 May 2020

HAL is a multi-disciplinary open access archive for the deposit and dissemination of scientific research documents, whether they are published or not. The documents may come from teaching and research institutions in France or abroad, or from public or private research centers.
L'archive ouverte pluridisciplinaire HAL, est destinée au dépôt et à la diffusion de documents scientifiques de niveau recherche, publiés ou non, émanant des établissements d'enseignement et de recherche français ou étrangers, des laboratoires publics ou privés. 


\section{Accepted Manuscript}

Anaerobic digester bioaugmentation influences quasi steady state performance and microbial community

K. Venkiteshwaran, K. Milferstedt, J. Hamelin, D.H. Zitomer

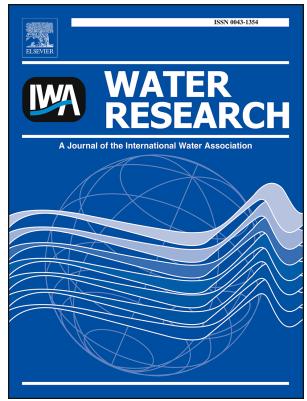

PII:

S0043-1354(16)30612-1

DOI:

10.1016/j.watres.2016.08.012

Reference: WR 12283

To appear in: Water Research

Received Date: 28 March 2016

Revised Date: 3 August 2016

Accepted Date: 4 August 2016

Please cite this article as: Venkiteshwaran, K., Milferstedt, K., Hamelin, J., Zitomer, D.H., Anaerobic digester bioaugmentation influences quasi steady state performance and microbial community, Water Research (2016), doi: 10.1016/j.watres.2016.08.012.

This is a PDF file of an unedited manuscript that has been accepted for publication. As a service to our customers we are providing this early version of the manuscript. The manuscript will undergo copyediting, typesetting, and review of the resulting proof before it is published in its final form. Please note that during the production process errors may be discovered which could affect the content, and all legal disclaimers that apply to the journal pertain. 


\section{Anaerobic digester bioaugmentation influences quasi steady state}

\section{2 performance and microbial community}

3 K. Venkiteshwaran ${ }^{1 *}$, K. Milferstedt ${ }^{2}$, J. Hamelin ${ }^{2}$, D. H. Zitomer ${ }^{1}$

4 'Department of Civil, Construction and Environmental Engineering, Marquette University, P.O. Box 1881,

5 Milwaukee, WI 53233, USA

$6{ }^{2}$ INRA, UR0050, Laboratoire de Biotechnologie de l'Environnement, Avenue des Etangs, Narbonne F-11100,

$7 \quad$ France

$8 \quad$ *kaushik.venkiteshwaran@marquette.edu

$9 \quad$ Abstract

10 Nine anaerobic digesters, each seeded with biomass from a different source, were

11 operated identically and their quasi steady state function was compared. Subsequently,

12 digesters were bioaugmented with a methanogenic culture previously shown to increase

13 specific methanogenic activity. Before bioaugmentation, different seed biomass resulted

14 in different quasi steady state function, with digesters clustering into three groups

15 distinguished by methane $\left(\mathrm{CH}_{4}\right)$ production. Digesters with similar functional

16 performance contained similar archaeal communities based on clustering of Illumina

17 sequence data of the V4-V5 region of the $16 \mathrm{~S}$ rRNA gene. High $\mathrm{CH}_{4}$ production

18 correlated with neutral $\mathrm{pH}$ and high Methanosarcina abundance, whereas low $\mathrm{CH}_{4}$

19 production correlated to low $\mathrm{pH}$ as well as high Methanobacterium and DHVEG 6 family

20 abundance. After bioaugmentation, $\mathrm{CH}_{4}$ production from the high $\mathrm{CH}_{4}$-producing

21 digesters transiently increased by $11 \pm 3 \%$ relative to non-bioaugmented controls $(p<0.05$,

$22 \mathrm{n}=3$ ), whereas no functional changes were observed for medium and low $\mathrm{CH}_{4}$ producing

23 digesters that all had $\mathrm{pH}$ higher than 6.7. The $\mathrm{CH}_{4}$ production increase after

24 bioaugmentation was correlated to increased relative abundance of Methanosaeta and 
25 Methaospirillum originating from the bioaugment culture. In conclusion, different

26 anaerobic digester seed biomass can result in different quasi steady state $\mathrm{CH}_{4}$ production,

27 SCOD removal, $\mathrm{pH}$ and effluent VFA concentration in the timeframe studied. The

28 bioaugmentation employed can result in a period of increased methane production. Future

29 research should address extending the period of increased $\mathrm{CH}_{4}$ production by employing

$30 \mathrm{pH}$ and VFA control concomitant with bioaugmentation, developing improved

31 bioaugments, or employing a membrane bioreactor to retain the bioaugment.

\section{$32 \underline{\text { Keywords }}$}

33 Digester efficiency; Methanobacterium, Methanosaeta, Methanosarcina,

34 Methanospririllum; Next generation sequencing 


\section{$35 \quad \underline{\text { 1. Introduction }}$}

36 Adding beneficial microorganisms to anaerobic digesters (i.e. bioaugmentation) has been

37 shown to increase degradation rates of specific organics and reduce upset digester

38 recovery time (Guiot et al. 2000; Hajji et al. 2000; Guiot et al. 2002; Cirne et al. 2006;

39 Schauer-Gimenez et al. 2010; Tale et al. 2011). Anaerobic digester bioaugmentation may

40 be more widely applicable if a culture was enriched to target a key, ubiquitous

41 intermediate in existing anaerobic processes. The existing anaerobic processes typically

42 treat readily degradable substrates, such as food production and dairy wastewater. When

43 treating readily degradable substrates, one ubiquitous and potentially problematic

44 intermediate is propionate (Schauer-Gimenez et al. 2010; Tale et al. 2015). Propionate

45 accumulation is often an indicator of process imbalance in anaerobic digesters which can

46 be caused by organic overload, nutrient deficiency, toxicant exposure or other factors

47 (Mccarty \& Smith 1986; Speece et al. 2006; Ma et al. 2009). The subsequent recovery

48 time of upset digesters depends on the abundance of microorganisms that can

49 biotransform an intermediate (i.e. propionate) or inhibitory compound into less harmful

50 products (Herrero \& Stuckey 2014).

51 Intermediates such as propionate can be biotransformed by a specific consortium of

52 synergistic microorganisms (McCarty \& Smith 1986; Speece et al. 2006). Bioconversion

53 of propionate to acetate and hydrogen $\left(\mathrm{H}_{2}\right)$ is thermodynamically favorable only when the

54 partial pressure of the generated $\mathrm{H}_{2}$ remains below $10^{-4}$ atm. Thus, degradation of

55 propionate requires a synergistic relationship between $\mathrm{H}_{2}$ producing and $\mathrm{H}_{2}$ consuming

56 microorganisms to maintain low $\mathrm{H}_{2}$ concentrations (McCarty \& Smith 1986). It was

57 shown previous that adding cultures enriched to consume $\mathrm{H}_{2}$ or propionate to anaerobic community. Water Research, 104, 128-136. DOI : 10.1016/j.watres.2016.08.012 
58 digesters can reduce recovery time after organic overload or toxicant exposure (Schauer-

59 Gimenez et al. 2010; Tale et al. 2011). Tale et al., (2015) employed aerotolerant

60 propionate consuming, methanogenic cultures for bioaugmentation. The aerotolerant

61 culture may be commercially beneficial since it can be easily handled and dried in

62 ambient air (Zitomer 2013). In addition, micro-aerated cultures outperformed a strictly

63 anaerobic culture when used for bioaugmentation, resulting in higher specific

64 methanogenic activity (SMA) against propionate and shorter recovery time after organic

65 overload (Tale et al. 2015).

66 Despite some success, anaerobic digester bioaugmentation is still at a nascent stage. A

67 comprehensive review published by Herrero \& Stuckey (2014) reported either transient

68 improvement in performance or a complete failure of bioaugmentation to improve

69 anaerobic digestion, but no instances of long-term improvement. Therefore, it is still

70 questionable whether or not adding a limited quantity of externally cultured

71 microorganisms can increase long-term methane production (Herrero \& Stuckey 2014).

72 Microbial community analysis has often been employed to understand the relationship

73 between microorganisms and digester function (Venkiteshwaran et al. 2016). However

74 changes in digester microbial communities after bioaugmentation have not been

75 extensively studied.

76 In this work, bioaugmentation using a methanogenic, aerotolerant propionate enrichment

77 culture was investigated as a possible method to improve methane production after quasi-

78 steady operation for anaerobic digesters fed a readily degradable waste. Nine groups of

79 anaerobic digesters were seeded with different starting biomass to obtain different 
80 microbial communities and digesters were then bioaugmented and monitored for changes

81 in function and microbial community using high throughput Illumina sequencing.

\section{2. Material and Methods}

$83 \quad 2.1$ Anaerobic digesters

84 Biomass samples were obtained from nine full-scale municipal anaerobic digesters in

85 different US states; Delaware (Set-D), Florida (Set-B), Michigan (Set-I), Mississippi

86 (Set-F), New Jersey (Set-H), Ohio (Set-E), South Dakota (Set-G), West Virginia (Set-C)

87 and Wyoming (Set-A) to obtain a variety of microbial communities. With the exception

88 of a thermophilic digester in Michigan, all other biomass samples were from mesophilic

89 digesters. All digesters were continuous stirred-tank reactors stabilizing municipal

90 wastewater sludge with solids retention times between 15 and 30 days. The Florida

91 digester was also fed food waste as a co-digestate.

92 Each biomass sample was used to seed two sub-sets (bioaugmented and non-

93 bioaugmented) of triplicate, $160-\mathrm{mL}$ lab-scale digesters with $50-\mathrm{mL}$ working volume and

94 biomass concentration of $8 \mathrm{~g}$ volatile solids (VS)/L. Digesters were operated at a 10-day

95 HRT and fed synthetic wastewater (non fat-dry milk) and basal nutrient media at an

96 organic loading rate (OLR) of $3 \mathrm{~g} \mathrm{COD/L-day.} \mathrm{The} \mathrm{digesters} \mathrm{were} \mathrm{operated} \mathrm{for} 60$ days

97 until they attained quasi-steady state operation during which the digester daily biogas

98 production coefficient of variation was less than 20\%. The bioaugmented digesters

99 received a daily dose of the enrichment culture from day 60 to 70 . The daily dose was

100 equivalent to $1 \%$ of the digester biomass total adenosine triphosphate (tATP) mass (this

101 was equivalent to $1.5-2 \%$ of the digester VS mass). Simultaneously, the non-

102 bioaugmented digesters received a COD equivalent dose of inactivated (autoclaved) community. Water Research, 104, 128-136. DOI : 10.1016/j.watres.2016.08.012 
103 enrichment culture. Functional parameters including effluent soluble COD (SCOD) and

104 volatile fatty acids (VFA) concentrations as well as biogas $\mathrm{CH}_{4}$ concentration were

105 monitored between days 60 and 80. Digester biomass samples were collected on day 71

106 for amplicon sequencing.

107 Cumulative methane volume produced was calculated by summing the daily methane

108 production volumes ( $\mathrm{ml} \mathrm{CH}_{4} /$ day) from days 60 to 80 . Biomass production rate was

109 calculated as the product of VSS concentration (mg VSS/L) and effluent flow (L/day).

110 Observed biomass yield was calculated as the quotient of biomass production rate and

111 COD added to the digester per day (mg COD/day).

$112 \quad$ 2.2 Enrichment culture for bioaugmentation

113 A moderately aerated, propionate-utilizing, mixed methanogenic enrichment culture

114 developed by Tale et al. (2011) was employed for bioaugmentation. The original seed

115 biomass for the enrichment culture was from an upflow anaerobic sludge blanket (UASB)

116 reactor treating brewery wastewater that exhibited a high methanogenic activity (Tale et

117 al. 2011). When previously used for bioaugmentation, this aerotolerant mixed microbial

118 culture reduced the recovery time of transiently organically overloaded digesters (Tale et

119 al. 2015). The enrichment was maintained in two completely mixed vessels with a

120 volume of four liters at $35{ }^{\circ} \mathrm{C}$ at a 15 day $\mathrm{HRT}$ and fed $0.17 \mathrm{~g}$ propionate/L-day as

121 calcium propionate with basal nutrient media. Immediately after feeding, ambient air was

122 added directly into the headspace of the vessel at a volume equivalent to $25 \mathrm{mg} \mathrm{O} / \mathrm{L}$-day

123 or $10 \%$ of the OLR to provide a micro-aerated environment.

$124 \quad 2.3$ Basal nutrient media 
125 Basal nutrient media, as described by Speece (2008), contained the following [mg/L]:

$126 \mathrm{NH}_{4} \mathrm{Cl}$ [400]; $\mathrm{MgSO}_{4} \cdot 6 \mathrm{H}_{2} \mathrm{O}$ [250]; $\mathrm{KCl}$ [400]; $\mathrm{CaCl}_{2} \cdot 2 \mathrm{H}_{2} \mathrm{O}$ [120]; $\left(\mathrm{NH}_{4}\right)_{2} . \mathrm{HPO}_{4}$ [80];

$127 \mathrm{FeCl}_{3} \cdot 6 \mathrm{H}_{2} \mathrm{O}$ [55]; $\mathrm{CoCl}_{2} \cdot 6 \mathrm{H}_{2} \mathrm{O}$ [10]; KI [10]; the trace metal salts $\mathrm{MnCl}_{2} \cdot 4 \mathrm{H}_{2} \mathrm{O}, \mathrm{NH}_{4} \mathrm{VO}_{3}$,

$128 \mathrm{CuCl}_{2} \cdot 2 \mathrm{H}_{2} \mathrm{O}, \mathrm{Zn}\left(\mathrm{C}_{2} \mathrm{H}_{3} \mathrm{O}_{2}\right)_{2} \cdot 2 \mathrm{H}_{2} \mathrm{O}, \mathrm{AlCl}_{3} \cdot 6 \mathrm{H}_{2} \mathrm{O}, \mathrm{Na}_{2} \mathrm{MoO}_{4} \cdot 2 \mathrm{H}_{2} \mathrm{O}, \mathrm{H}_{3} \mathrm{BO}_{3}, \mathrm{NiCl}_{2} \cdot 6 \mathrm{H}_{2} \mathrm{O}$,

$129 \mathrm{NaWO}_{4} \cdot 2 \mathrm{H}_{2} \mathrm{O}$, and $\mathrm{Na}_{2} \mathrm{SeO}_{3}$ [each at 0.5]; yeast extract [100]; $\mathrm{NaHCO}_{3}$ [6000]; and

130 resazurin $[1]$

$131 \quad 2.4$ Analytical methods

132 tATP concentration was analyzed using a commercial kit following the manufacturer

133 instructions (BacTiter-Glo, Promega, Madison WI, USA). The inactive culture added to

134 non-bioaugmented digesters was placed in an autoclave (Model 3870E, Tuttnauer Co.,

135 Hauppauge, NY, USA) at 15 Psi and $121^{\circ} \mathrm{C}$ for 30 minutes prior to augmentation

136 experiments. Daily biogas volume produced was measured by inserting a needle with a

137 wetted glass barrel syringe through serum bottle septa. SCOD was measured by filtering

138 the sample through a $0.45 \mu \mathrm{m}$ pore size membrane syringe filter and determining the

139 filtrate COD by standard methods (APHA et al., 1998). Biogas methane concentration

140 was measured by gas chromatography (GC System 7890A, Agilent Technologies, Irving,

141 TX, USA) using a thermal conductivity detector. VFA concentrations were measured by

142 gas chromatography (GC System 7890A, Agilent Technologies, Irving, TX, USA) using

143 a flame ionization detector. The VS, TSS and VSS analyses were performed by standard

144 methods (APHA et al., 1998). Statistical analysis such as two-sample Student's t-test

145 with unequal variance and Pearson's coefficient were calculated on Microsoft Excel 2010

146 (Version 14.3.2) using built in functions.

$147 \quad 2.5$ Microbial community analysis 
148 DNA was extracted from all bioaugmented and non-bioaugmented digesters (including

149 all replicates, $\mathrm{n}=54$ ) on Day 71 using the PowerSoil ${ }^{\mathrm{TM}}$ DNA Isolation Sample Kit

150 (MoBio Laboratories, Inc., Carlsbad, CA, USA) according to the manufacturer's

151 instructions. The biomass samples were subjected to bead beating on a vortex (Model

152 58816-121, VWR International, Radnor, PA, USA) for 10 minutes. Primer pair 515-532U

153 and 909-928U was used (Wang \& Qian 2009) including their respective linkers, to

154 amplify the V4-V5 region of the 16S rRNA gene over 30 amplification cycles at an

155 annealing temperature of $65{ }^{\circ} \mathrm{C}$. The primer pairs target both archaeal and bacterial $16 \mathrm{~S}$

156 rRNA genes. An index sequence was added in the second PCR of 12 cycles, and the

157 resulting products were purified and loaded onto the Illumina MiSeq cartridge for

158 sequencing of paired $300 \mathrm{bp}$ reads following manufacturer's instructions (v3 chemistry).

159 Sequencing and library preparation were performed at the Genotoul Lifescience Network

160 Genome and Transcriptome Core Facility in Toulouse, France (get.genotoul.fr). A

161 modified version of the standard operation procedure for MiSeq data (Kozich et al. 2013)

162 in Mothur version 1.35.0 (Schloss et al. 2009) was used to assemble forward and reverse

163 sequences and preclustering at 4 differences in nucleotides over the length of the

164 amplicon. Uchime was used for chimera checking (Edgar et al. 2011). Sequences that

165 appear less than three times in the entire data set were removed. Alignment of the $16 \mathrm{~S}$

166 rRNA sequences was done using SILVA SSURef NR99, release 119, as provided by

167 Mothur (Schloss et al. 2009). The same database was used in Mothur's classify.seqs()

168 command to assign taxonomic affiliation using a cutoff value of $80 \%$. Custom R scripts

169 were used to perform dual hierarchical clustering (using R command hclust and heatmap)

170 and nonmetric multidimensional scaling (nMDS) (using the default Bray-Curtis index), 
171 of anaerobic community sequence data gathered from Illumina sequencing (Carey et al.

172 2016; McNamara \& Krzmarzick 2013).

\section{3. Results and Discussion}

174 All nine digester sets reach quasi-steady state based on less than $20 \%$ coefficient of

175 variation in daily biogas production by day 60 when bioaugmentation was initiated

176 (Figure 1 and S1). Effluent VFA concentrations for all digesters were higher than $2 \mathrm{~g} / \mathrm{L}$

177 and methane production was below $70 \%$ of the theoretical value assuming all COD was

178 converted to methane. Therefore, residual COD was available and could possibly be

179 removed if system changes occurred. This challenged condition was desired so that

180 bioaugmentation effects could be observed. During the dosage period, autoclaved

181 propionate enrichment culture was added to the non-bioaugmented digesters, whereas

182 live propionate enrichment culture was added to the bioaugmented digesters. Adding

183 inactivated enrichment culture did not result in a statistical change in biogas production

184 rate (Figure 1 and S1). This was expected since the daily COD fed to the digesters from

185 the augments was low and was less than $8 \%$ of the total synthetic wastewater COD fed.

186 3.1 Non-bioaugmented digester function

187 Although operated identically, the digester sets did not achieve identical operational

188 values. For example, the quasi steady state methane production rates ranged from 0.3 to

$1890.8 \mathrm{~L} \mathrm{CH}_{4}$ per $\mathrm{L}$ of digester per day $\left(\mathrm{L} \mathrm{CH}_{4} / \mathrm{L}_{\mathrm{R}}\right.$-day) (Table 1). Each non-bioaugmented

190 digester set was classified into one of three distinct groups based on statistically similar

191 methane production rate, SCOD removal, $\mathrm{pH}$ and effluent acetate concentration ( $\mathrm{p}$ value

$192<0.05, \mathrm{n}=3$ ) (Table 1). Group 1 (G1) (sets A, B and C) contained the best performing

193 digesters with the highest methane production rate, highest SCOD removal rate, highest community. Water Research, 104, 128-136. DOI : 10.1016/j.watres.2016.08.012 
$194 \mathrm{pH}$ and lowest effluent acetate concentration; Group 2 (G2) (sets D, E, F and G) showed

195 intermediary performance and Group 3 (G3) (sets H and I) contained the poorest

196 performing digesters with the lowest methane production rate, lowest SCOD removal

197 rate, lowest $\mathrm{pH}$ and highest effluent acetate concentration (Figure 2). The functional

198 variation among digester sets can be attributed to the differences in the microbial

199 communities the seed biomass used for each set. Future research is warranted to elucidate

200 quantitative relationships between microbial community descriptors and digester function

201 so that the suitability of various seed biomass samples can be estimated. This would be

202 helpful to identify the most suitable biomass for a given process startup or re-seeding

203 application.

204 3.2 Non-bioaugmented digester archaeal community

205 A total of 32 archaeal OTUs, based on $97 \%$ similarity, were identified among all the 206 digester samples analyzed. The relative abundance of archaeal sequences varied from 1 to $2074 \%$ for $\mathrm{G} 1, \mathrm{G} 2$ and 0.1 to $1 \%$ for G3 digesters, respectively. Eight archaeal OTUs

208 represented more than $99 \%$ of the archaeal abundance in all non-bioaugmented digesters

209 (Figure S2). These eight OTUs were most similar to the genera Methanofollis,

210 Methanosarcina, Methanospirillum, Methanosaeta, Methanobacterium, Candidatus

211 Methanomethylophilus and two unclassified genera in the order WCHA1-57 and the

212 family Deep Sea Hydrothermal Vent Grp 6 (DHVEG 6), based on the SILVA SSURef

213 NR99 v119 reference database from Mothur (Schloss et al. 2009) (Figure S2).

214 The nine non-bioaugmented digester sets clustered in the same three groups that were

215 identified by functional data (95\% confidence interval) (Figure 3). Digesters with similar

216 functional performance contained similar archaeal communities. Non-bioaugmented G1 community. Water Research, 104, 128-136. DOI : 10.1016/j.watres.2016.08.012 
217 digester communities were distinguished from G2 and G3 communities by high relative

218 abundance of Methanosarcina, which ranged from 60 to $95 \%$ of archaea in G1 digesters

219 (Figure S2). Methanobacterium dominated non-bioaugmented G2 digesters, with a

220 relative abundance that ranged from 80 to $99 \%$ of the archaeal diversity. The G3

221 digesters were distinguished by high relative abundance of the DHVEG 6 family, with

222 Methanobacterium also observed in high relative abundance (Figure S2).

223 Methanosarcina and Methanosaeta are the only two methanogenic genera known to

224 consume acetate (Liu \& Whitman 2008). High relative abundance of Methanosarcina in

225 the high-performing G1 digesters correlated to higher methane production and lower

226 effluent acetate concentration. This is ostensibly because the Methanosarcina maximum

227 specific substrate utilization rate is higher than that of Methanosaeta (Liu \& Whitman

228 2008). Therefore, the presence of Methanosarcina in digesters with moderate to high

229 VFA concentrations, such as the ones of this study, may be beneficial to maintain more

230 rapid bioconversion of acetate to methane. Compared to G1 digesters, Methanosarcina

231 relative abundance in the lesser performing, non-bioaugmented G2 digesters was lower,

232 ranging from 0.5 to $18 \%$. In addition, Methanosarcina was undetectable in the poorest

233 performing, non-bioaugmented G3 digesters which had the highest acid concentrations

234 and lowest $\mathrm{pH}$.

235 The poor performing G3 digesters were distinguished from the better performing G1 and

236 G2 digesters by the low archaeal sequence abundance $(\leq 1 \%$ of the total sequence) and

237 further by high relative abundance of DHVEG 6, which ranged from 60-90\% in G3

238 digesters (Figure S2). DHVEG 6 have been observed in acidic environments, marine

239 environments, terrestrial soils, hydrothermal sediments, deep sea methane seep community. Water Research, 104, 128-136. DOI : 10.1016/j.watres.2016.08.012 
240 sediments, rice paddy soil and saline lakes (Casamayor et al. 2013; Nunoura et al. 2010;

241 Nunoura et al. 2011; Hugoni et al. 2013; Grosskopf et al. 1998). Given that DHVEG6

242 microorganisms have been observed in extreme environmental conditions that typically

243 are not present in a healthy functioning digester, high abundance of DHVEG 6 in

244 anaerobic digesters ostensibly indicates an upset digester with low $\mathrm{pH}$ and low biogas

245 production such as the G3 digesters.

246 3.3 Non-bioaugmented digester bacterial community

247 Approximately 1300 bacterial OTUs were identified based on 97\% similarity among all

248 the biomass samples analyzed in this study. The 29 OTUs having the highest relative

249 abundance among all the digesters and the enrichment culture were considered for

250 bacterial community analysis. These 29 OTUs contributed $70-85 \%$ of the total bacterial

251 sequences in the non-bioaugmented digesters.

252 The nine digesters bacterial communities formed two clusters, with G1 and G2 non-

253 bioaugmented digesters forming one bacterial cluster and G3 non-bioaugmented digesters

254 in the second bacterial cluster (Figure 4). Bacterial communities in all nine digester sets

255 were dominated by OTUs most similar to fermenters belonging to the phyla Firmicutes,

256 Bacteroidetes and Synergistetes (Figure S3). The most common bacterial OTUs that were

257 observed in the digesters were the genera Bacteroides, Peptostreptococcus,

258 Pyramidobacter, Aminobacterium, Atopobium and RC9 Gutgroup. Non-bioaugmented

259 G1 and G2 digesters were distinguished from G3 digesters by the higher abundance of

260 the genera Porphyromonas, Petrimonas and unclassified FamilyXI, whereas non-

261 bioaugmented G3 digesters were dominated by OTUs most similar to RC9 Gut Group community. Water Research, 104, 128-136. DOI : 10.1016/j.watres.2016.08.012 
262 microorganisms which contributed more than $60 \%$ of the total bacterial relative

263 abundance (Figure S3).

$264 \quad 3.4$ Enrichment culture

265 The enrichment culture functional parameters were stable between days 60 to 80 , with

$26699 \%$ SCOD removal, no detectable VFAs, $\mathrm{pH}$ of $7.5 \pm 0.2,60 \pm 3 \%$ biogas methane

267 content, methane yield of $330 \pm 16 \mathrm{mLCH}_{4} / \mathrm{g}$-COD removed and observed biomass yield

268 of $0.08 \pm 0.01 \mathrm{gVSS} / \mathrm{gCOD}$.

269 More than 700 bacterial OTUs were identified in the enrichment culture based on $97 \%$

270 similarity. The 25 bacterial OTUs with the highest relative abundance represented

271 approximately $80 \%$ of total bacterial sequences and are shown in Figure S4. The two

272 most abundant bacterial taxa were most similar to an unclassified genus within

273 Spirochaetaceae (30\% of the total bacterial relative abundance) and Thermovirga within

274 Synergistaceae (12\% of the total bacterial relative abundance) (Figure S4). Thermovirga

275 is currently represented by a single member species Thermovirgalienii, which is a

276 moderately thermophillic, amino acid degrading fermentative bacterium (Dahle 2006).

277 Some members of the Spirochaetaceae family such as Treponema species, are reported to

278 be abundant in iron-reducing consortia that were used by othersto bioaugmentanaerobic

279 digesters (Baek et al. 2015). Bacteria related to Spirochaetes may be beneficial for the

280 overall process since some of them have been suggested as syntrophic acetate-oxidizing

281 bacteria (Hattori 2008; Lee et al. 2013; Lee et al. 2015). Iron-reducing bacteria (IRB) are

282 commonly observed in anaerobic systems and can utilize acetate, $\mathrm{H}_{2}$, ethanol and other

283 complex substrates and ferric iron as an electron acceptor (Kim et al. 2014). They are

284 also known to form syntrophic associations and, via interspecies electron transfer, community. Water Research, 104, 128-136. DOI : 10.1016/j.watres.2016.08.012 
285 transfer electron directly to their methanogenic partner, which can facilitate $\mathrm{CO}_{2}$ reduction

286 to $\mathrm{CH}_{4}$ (Stams \& Plugge 2009; Rotaru et al. 2014). Addition of an IRB consortium has

287 been shown to increase the methane production rate in anaerobic digesters (Baek et al.

288 2015).

289 Given that the enrichment culture was fed calcium propionate, it was expected that

290 bacteria associated with syntrophic propionate degradation would be abundant. Of the

291 known bacterial genera with members capable of degrading propionate, Desufobulbus,

292 Smithella, and Syntrophobacter were observed with a combined relative abundance of

293 9\% (De Bok et al. 2001; De Bok et al. 2004; Stams \& Plugge 2009), with Desulfobulbus

294 contributing 7\% (Figure S4).

29515 archaeal OTUs were detected in the enrichment culture based on 97\% similarity, of

296 which 6 OTUs contributed more than 99\% of the total archaeal sequences (Figure S5).

297 Archaeal sequences constituted approximately 5-6\% of the total sequences detected in the

298 enrichment culture. The archaeal community was dominated by sequences most similar

299 to Methanosaeta, constituting 65\% of the total archaeal sequences (Figure S5).

300 Methanosarcina constituted only $1.2 \%$ of the total archaeal sequences in the enrichment

301 culture (Figure S5). Unlike Methanosarcina, Methanosaeta have a high substrate affinity

302 and a lower maximum specific substrate utilization rate. Hence, Methanosaeta usually

303 dominate over Methanosarcina in cultures such as the enrichment culture in this study

304 having acetate concentrations lower than $500 \mathrm{mg} / \mathrm{L}$ (Liu \& Whitman 2008).

305 Apart from acetoclastic methanogens, the enrichment culture archaeal composition

306 consisted of OTUs most similar to known hydrogenotrophic methanogens including

307 Methanospirillum, Methanobacterium, Methanolinea and an unclassified genus in the community. Water Research, 104, 128-136. DOI : 10.1016/j.watres.2016.08.012 
308 order WCHA1-57 (Figure S5) (Liu \& Whitman 2008). Conversion of propionate to

309 methane only becomes thermodynamically favorable through $\mathrm{H}_{2}$ utilization. Therefore,

310 the significant presence of hydrogenotrophic methanogens contributing $30-35 \%$ of the

311 total archaeal sequences could have positive functional results. The presence of

312 microorganisms classified in the genera Methanospirillum, Methanobacterium,

313 Methanolinea has previously been reported to play an important role in propionate

314 utilization during digester recovery after organic overload (Tale et al. 2011; Tale et al.

315 2015; Schauer-Gimenez et al. 2010).

316 The archaeal order WCHA1-57 was observed at a significant relative abundance (12\%) in

317 the enrichment culture. Although many WCHA1-57-related 16S rRNA gene sequences

318 have been identified in anaerobic digesters (Chouari et al. 2005; Rivière et al. 2009;

319 Schauer-Gimenez et al. 2010), no reports were found regarding their role in propionate

320 oxidation or methane production. In some anaerobic digesters treating municipal sewage

321 sludge, the WCHA1-57 phylotype population represented one of the predominant

322 archaeal components, with relative abundance $>70 \%$ in archaeal clone libraries (Chouari

323 et al. 2005; Rivière et al. 2009). These observations indicate that WCHA1-57 archaea

324 represent a potentially important group in anaerobic digesters. Chouari et al. (2005)

325 reported the enrichment of WCHA1-57 phylotypes in cultures fed formate or $\mathrm{H}_{2} / \mathrm{CO}_{2}$.

326 This indicates that WCHA1-57 plays a role in reducing hydrogen concentration and,

327 therefore, aiding in conversion of propionate to methane.

328 Both bacterial and archaeal enrichment culture communities were distinct from those of

329 the nine digester sets. The nMDS scaling plots based on the top eight archaeal (Figure 3)

330 and 29 bacterial (Figure 4) OTUs, selected based on their relative abundance and 
331 prevalence among all the biomass samples, shows distinct clustering of the enrichment

332 culture separate from the G1, G2 and G3 non-bioaugmented and bioaugmented digesters.

333 3.5 Bioaugmentation, digester function and microbial community changes

334 Cumulative methane produced by both non-bioaugmented and bioaugmented digesters

335 between days 60 and 80 were calculated and compared to observe any difference in

336 performance (Figure 5). Only the three G1 digester sets A, B and C showed a statistically

337 significant increase $(\mathrm{P}<0.05, \mathrm{n}=3)$ in average methane production of $11 \pm 3 \%$ after

338 bioaugmentation, with increases of $9 \pm 1 \%, 12 \pm 2 \%$ and $13 \pm 2 \%$, respectively, compared to

339 non-bioaugmented controls (Figure 5).

340 The increased methane production in G1 digestersafter bioaugmentation was not

341 sustained. The period of increased methane production averaged 9 days, and was 7,11

342 and 9 days for sets A, B and C, respectively (Figure 1, S1A and S1B). Also, the increased

343 methane production did not occur immediately after bioaugmentation was initiated. The

344 lag between the dosage period start (Day 60) and the first day of increased methane

345 production for set $\mathrm{A}, \mathrm{B}$ and $\mathrm{C}$ bioaugmented digesters averaged 10 days, and was 12,8

346 and 9 days, respectively (Figure 1, S1A and S1B).

347 The archaeal communities in the bioaugmented digesters were grouped into three distinct

348 clusters based on archaeal sequences (Figure 3). The archaeal community of the

349 bioaugmented digesters belonging to functional groups G2a and G3a, which did not

350 improve after bioaugmentation, did not significantly change after bioaugmentation

351 (Figure 3). In contrast, however, the G1 bioaugmented digesters showed a statistical

352 improvement in methane production and the archaeal community changed significantly 
353 after bioaugmentation (Figure 3). After bioaugmentation, the archaeal community of G1

354 digesters became more similar to that of the enrichment culture (G4).

355 The community structure shift in G1 digesters after bioaugmentation was primarily

356 caused by the increased abundance of two archaeal genera: Methanosaeta and

357 Methanospirillum (Figure 6), which are in high abundance in the enrichment culture

358 (Figure S5). In contrast, the relative abundance values of Methanosaeta and

359 Methanospirillum were very low $(<1 \%)$ in $\mathrm{G} 2$ and below detection in the G3

360 bioaugmented digesters, respectively. The bacterial community compositions of the

361 bioaugmented digesters did not show any significant shift after bioaugmentation (Figure

362 4). Sequences related to the two most abundant bacterial genera observed in the

363 enrichment culture, unclassified Spirochaeata and Thermovirga, which were not detected

364 in the non-bioaugmented digesters, were detected in all the bioaugmented digesters, but

365 their relative abundance remained below $1 \%$ after bioaugmentation.

366 The resulting increase in methane production observed in G1 digesters from

367 bioaugmentation was associated with a shift in the archaeal community structure.

368 Increased relative abundance of the genera Methanosaeta and Methaospirillum was

369 observed in digesters with improvement in the methane production rate. The relative

370 abundance of Methanosaeta and Methanospirillum increased from below detection in the

371 non-bioaugmented digesters to $10-40 \%$ and $10-30 \%$, respectively, in the bioaugmented

372 G1 digesters (Figure 6). However, it is important to note that the methane production

373 rate increase lasted only 7 to 11 days in the bioaugmented G1 digesters. This could be

374 due to washout of Methanosaeta and Methanospirillum once bioaugmentation ceased. It

375 may be possible to improve the methane production further by increasing the dose of the community. Water Research, 104, 128-136. DOI : 10.1016/j.watres.2016.08.012 
enrichment biomass or extending the duration of the dosage period. In addition microbial

377 carriers, such as alginate beads or granular activated carbon, or membrane bioreactors

378 could be used to retain the bioaugment in the bioreactor.

379 The enrichment culture used in this study was produced at a $\mathrm{pH}$ of 7.5 with no detectable

380 VFAs present. The most abundant methanogens in the enrichment culture, Methanosaeta

381 and Methanospiririllum (i.e., M. hungatii), are sensitive to low $\mathrm{pH}$ and high acid or

382 propionate concentrations (Liu \& Whitman 2008; Barredo \& Evison 1991). It is likely

383 that the methane production increase in G1 digesters after bioaugmentation was due to

384 the relatively low VFA concentration and neutral $\mathrm{pH}$, which was conducive for the

385 activity of Methanosaeta and Methanospiririllum added via the bioaugment. In contrast,

386 the low $\mathrm{pH}$, high VFA concentration environment in G2 and G3 digesters may have

387 inhibited the enrichment culture microorganisms. Therefore, the environment the

388 enrichment culture is being added into must be carefully considered and additional steps

389 such as acclimating the augment culture or increasing the digester $\mathrm{pH}$ before

390 bioaugmentation may be required to increase methane production and COD removal by

391 bioaugmentation.

\section{4. Conclusion}

393 Different anaerobic digester seed biomass can result in significantly different quasi

394 steady state functional parameters, including methane production rate, SCOD removal,

$395 \mathrm{pH}$ and effluent VFA concentration. Therefore, care should be taken to select seed

396 biomass with high activity for digester startup or re-seeding.

397 Identically operated digesters that contain different archaeal communities can exhibit 398 different functional characteristics during quasi steady state operation. When operating 
399 under challenging conditions, digesters with high methane production rates can be

400 distinguished by high Methanosarcina relative abundance. The presence of

401 Methanosarcina in digesters with moderate to high VFA concentrations is beneficial to

402 maintain more rapid bioconversion of acetate to methane. In contrast, digesters with low

403 methane production can be distinguished by high abundance of Methanobacterium and

404 DHVEG 6 family organisms. Since DHVEG6 microorganisms have been found in

405 extreme environments, including deep-sea hydrothermal vents, their high abundance in

406 anaerobic digesters may indicate past or current digester upset (i.e., high VFA

407 concentration and low methane production).

408 Bioaugmentation with a methanogenic, propionate degrading enrichment culture resulted

409 in a significant increase in methane production when digester $\mathrm{pH}$ was neutral or greater.

410 However, methane production did not change after bioaugmenting digesters that had $\mathrm{pH}$

411 values less than neutral. Therefore, when predicting bioaugmentation outcomes, the

412 environment into which an augment culture is added must be carefully considered as well

413 as the composition of the bioaugment itself. Steps such as increasing low digester $\mathrm{pH}$

414 before bioaugmentation may be necessary to improve digester function.

415 The methane production increase after bioaugmentation was correlated with increased

416 relative abundance of Methanosaeta and Methaospirillum that were in the bioaugment

417 culture employed. However, the methane production rate increase was only temporary.

418 More research is warranted to develop sustained, steady state improvements via

419 bioaugmentation or bioaugmentation combined with $\mathrm{pH}$ adjustment for challenged 420 digesters.

\section{$421 \quad$ Acknowledgements}


422 The authors thank the following individuals for their laboratory contributions: Mike

423 Dollhopf (Water Quality Center, Marquette University, Milwaukee USA) and Dr. Jean-

424 Philippe Steyer (Laboratory of Environmental Biotechnology, Narbonne, France).

\section{References}

426 American Public Health Association (APHA), American Water Works Association

427 (AWWA), Water Environment Federation (WEF), et al., 1998. Standard Methods

428 for the Examination of Water and Wastewater, twentieth ed.

429 Baek, G., Kim, J., Shin, S. G., \& Lee, C. (2016). Bioaugmentation of anaerobic sludge

430 digestion with iron-reducing bacteria: process and microbial responses to variations

431 in hydraulic retention time. Applied Microbiology and Biotechnology, 100(2), 927-

432 37. doi:10.1007/s00253-015-7018-y.

433 Barredo, M. S., \& Evison, L. M. (1991). Effect of propionate toxicity on methanogenenriched sludge, Methanobrevibacter smithii, and Methanospirillum hungatii at different pH values. Applied and Environmental Microbiology, 57(6), 1764-9.

436 Carey, D. E., Zitomer, D. H., Hristova, K. R., Kappell, A. D., \& McNamara, P. J. (2016).

Casamayor, E. O., Triadó-Margarit, X., \& Castañeda, C. (2013). Microbial biodiversity

443 Chouari, R., Le Paslier, D., Daegelen, P., Ginestet, P., Weissenbach, J., \& Sghir, A.

444 (2005). Novel predominant archaeal and bacterial groups revealed by molecular 
analysis of an anaerobic sludge digester. Environmental Microbiology, 7(8), 110415. doi:10.1111/j.1462-2920.2005.00795.x.

447 Cirne, D. G., Björnsson, L., Alves, M. M., \& Mattiasson, B. (2006). Effects of bioaugmentation by an anaerobic lipolytic bacterium on anaerobic digestion of lipidrich waste. 81(11), 1745-52. doi: 10.1002/jctb.1597.

Dahle, H. (2006). Thermovirga lienii gen. nov., sp. nov., a novel moderately oil well. International journal of systematic and evolutionary microbiology, 56(7), 1539-45. doi:10.1099/ijs.0.63894-0.

De Bok, F. A., Plugge, C. M., \& Stams, A. J. M. (2004). Interspecies electron transfer in

De Bok, F. A., Stams, A. J. M., Dijkema, C., \& Boone, D. R. (2001). Pathway of propionate oxidation by a syntrophic culture of Smithella propionica and Methanospirillum hungatei. Applied and Environmental Microbiology, 67(4), 18004. doi: 10.1128/AEM.67.4.1800-1804.2001

Edgar, R. C., Haas, B. J., Clemente, J. C., Quince, C., \& Knight, R. (2011). UCHIME improves sensitivity and speed of chimera detection. Bioinformatics (Oxford,

464 Grosskopf, R., Janssen, P. H., \& Liesack, W. (1998). Diversity and structure of the 465 methanogenic community in anoxic rice paddy soil microcosms as examined by 466 cultivation and direct $16 \mathrm{~S}$ rRNA gene sequence retrieval. Applied and 467 Environmental Microbiology, 64(3), 960-9. 
http://aem.asm.org/content/64/3/960.full.pdf+html

469 Guiot, S. R., Tartakovsky, B., Lanthier, M., Lévesque, M. J., Manuel, M. F., Beaudet, R.,

470 Greer C. W., \& Villemur, R. (2002). Strategies for augmenting the

471 pentachlorophenol degradation potential of UASB anaerobic granules. Water

472 Science and Technology : A Journal of the International Association on Water

473 Pollution Research, 45(10), 35-41. http://www.ncbi.nlm.nih.gov/pubmed/12188570

474 Guiot, S. R., Tawfiki Hájji, K., \& Lépine, F. (2000). Immobilization strategies for

475 bioaugmentation of anaerobic reactors treating phenolic compounds. Water Science

476 and Technology, 42(5), 245-50. http://wst.iwaponline.com/content/ppiwawst/42/5-

$477 \quad$ 6/245.full.pdf.

478 Hajji, K. T., Lépine, F., Bisaillon, J. G., Beaudet, R., Hawari, J., \& Guiot, S. R. (2000).

479 Effects of bioaugmentation strategies in UASB reactors with a methanogenic

480 consortium for removal of phenolic compounds. Biotechnology and Bioengineering, 67(4), 417-23. doi:10.1002/(SICI)1097-0290(20000220)67:4<417::AID-

Hattori, S. (2008). Syntrophic acetate-oxidizing microbes in methanogenic environments. Microbes and Environments / JSME, 23(2), 118-27. http://www.ncbi.nlm.nih.gov/pubmed/21558697.

Herrero, M., \& Stuckey, D. C. (2014). Bioaugmentation and its application in wastewater treatment: A review. Chemosphere, 44. doi:10.1016/j.chemosphere.2014.10.033.

488 Hugoni, M., Taib, N., Debroas, D., Domaizon, I., Jouan Dufournel, I., Bronner, G., Salter 489 I., Agogué H., Mary I., Galand, P. E. (2013). Structure of the rare archaeal biosphere 490 and seasonal dynamics of active ecotypes in surface coastal waters. Proceedings of 
the National Academy of Sciences of the United States of America, 110(15), 60049. doi:10.1073/pnas.1216863110.

Jumas Bilak, E., Roudière, L., \& Marchandin, H. (2009). Description of "Synergistetes" phyl. nov. and emended description of the phylum "Deferribacteres" and of the family Syntrophomonadaceae, phylum “Firmicutes”. International Journal of Systematic and Evolutionary Microbiology, 59(Pt 5), 1028-35. doi:10.1099/ijs.0.006718-0.

Kozich, J. J., Westcott, S. L., Baxter, N. T., Highlander, S. K., \& Schloss, P. D. (2013). Development of a dual-index sequencing strategy and curation pipeline for doi:10.1128/AEM.01043-13.

Lee, S. H., Park, J. H., Kang, H. J., Lee, Y. H., Lee, T. J., \& Park, H. D. (2013). Distribution and abundance of Spirochaetes in full-scale anaerobic digesters. Bioresource Technology, 145, 25-32. doi:10.1016/j.biortech.2013.02.070. of syntrophic acetate oxidation by Spirochaetes during anaerobic methane production. Bioresource Technology, 190, 543-549.

510 Liu, Y., \& Whitman, W. B. (2008). Metabolic, phylogenetic, and ecological diversity of the methanogenic archaea. Annals of the New York Academy of Sciences, 1125, 171-89. doi:10.1196/annals.1419.019.

Ma, J., Carballa, M., Van De Caveye, P., \& Verstraete, W. (2009). Enhanced propionic 
acid degradation (EPAD) system: proof of principle and feasibility. Water Research, 43(13), 3239-48. doi:10.1016/j.watres.2009.04.046.

McCarty, P. L., \& Smith, D. P. (1986). Anaerobic wastewater treatment. Environmental Science \& Technology, 20(12), 1200-6. doi:10.1021/es00154a002.

McNamara, P. J., \& Krzmarzick, M. J. (2013). Triclosan enriches for Dehalococcoideslike Chloroflexi in anaerobic soil at environmentally relevant concentrations. FEMS Microbiology Letters, 344(1), 48-52. doi:10.1111/1574-6968.12153.

Nunoura, T., Takaki, Y., Kazama H., Hirai M., Ashi J., Imachi H., \& Kazama, H. (2012). Microbial diversity in deep-sea methane seep sediments presented by SSU rRNA

Nunoura, T., Oida, H., Nakaseama, M., Kosaka, A., Ohkubo, S. B., Kikuchi, T., Kazama gene tag sequencing. Microbes and Environments, 27(4), 382 - 390.

Rivière, D., Desvignes, V., Pelletier, E., Chaussonnerie, S., Guermazi, S., Weissenbach F.,Tsunogai U., Ishibashi J., Takai, K. (2010). Archaeal diversity and distribution along thermal and geochemical gradients in hydrothermal sediments at the Yonaguni Knoll IV hydrothermal field in the Southern Okinawa trough. Applied and Environmental Microbiology, 76(4), 1198-211.doi:10.1128/AEM.00924-09.

J., Li T., Camacho P., \& Sghir A. (2009). Towards the definition of a core of microorganisms involved in anaerobic digestion of sludge. The ISME Journal, 3(6), 700-14. doi:10.1038/ismej.2009.2.

Rotaru, A. E., Shrestha, P. M., Liu, F., Shrestha, M., Shrestha, D., Embree, M., Zengler K., Wardman C., Nevin K. P., \& Lovley D. R. (2014). A new model for electron 
flow during anaerobic digestion: direct interspecies electron transfer to

Methanosaeta for the reduction of carbon dioxide to methane. Energy \& Environmental Science, 7(1), 408-15. doi:10.1039/c3ee42189a.

540 Schauer Gimenez, A. E., Zitomer, D. H., Maki, J. S., \& Struble, C. A. (2010).

541 Bioaugmentation for improved recovery of anaerobic digesters after toxicant

542 exposure. Water Research, 44(12), 3555-3564. doi:10.1016/j.watres.2010.03.037.

543 Schloss, P. D., Westcott, S. L., Ryabin, T., Hall, J. R., Hartmann, M., Hollister, E. B.,

544 Lesniewski R. A., Oakley B. B., Parks D. H., Robinson C. J., Sahl J. W., Stres B.,

545 Thallinger G. G., Van Horn D. J., \& Weber C. F. (2009). Introducing mothur: open-

546 source, platform-independent, community-supported software for describing and

547 comparing microbial communities. Applied and Environmental Microbiology,

$548 \quad$ 75(23), 7537-41. doi:10.1128/AEM.01541-09.

549 Speece, R E, Saroch Boonyakitsombut, Moonil Kim, Nuri Azbar, and Pepi Ursillo. 2006.

$550 \quad$ "Overview of Anaerobic Treatment: Thermophilic and Propionate Implications."

551 Water Environment Research : A Research Publication of the Water Environment

552 Federation 78 (5): 460-73. http://www.ncbi.nlm.nih.gov/pubmed/16752608.

553 Speece, R. E. (2008). Anaerobic Biotechnology and Odor/corrosion Control for

554 Municipalities and Industries. Fields Publishing, Inc., Nashville, TN. ISBN: 1-

$555 \quad 57843-052-9$

556 Stams, A. J. M., \& Plugge, C. M. (2009). Electron transfer in syntrophic communities of 557 anaerobic bacteria and archaea. Nature Reviews Microbiology, 7(8), 568-77.

$558 \quad$ doi:10.1038/nrmicro2166.

559 Tale, V. P., Maki, J. S., Struble, C. A., \& Zitomer, D. H. (2011). Methanogen community 
structure-activity relationship and bioaugmentation of overloaded anaerobic

561 digesters. Water Research, 45(16), 5249-56. doi:10.1016/j.watres.2011.07.035.

562 Tale, V. P., Maki, J. S., \& Zitomer, D. H. (2015). Bioaugmentation of overloaded

563 anaerobic digesters restores function and archaeal community. Water Research, 70,

564 138-147. doi:10.1016/j.watres.2014.11.037.

565 Venkiteshwaran, K., Bocher, B., Maki, J., \& Zitomer, D. (2016). Relating Anaerobic

566 Digestion Microbial Community and Process Function. Microbiology Insights, 8(2),

567 37-44. doi:10.4137/MBI.S33593.

568 Wang, Y., \& Qian, P.-Y. (2009). Conservative fragments in bacterial 16S rRNA genes

569 and primer design for 16S ribosomal DNA amplicons in metagenomic studies. PloS

$570 \quad$ One, 4(10), e7401. doi:10.1371/journal.pone.0007401.

571 Zitomer, D. (2013) Preservation of Methanogenic, Hydrogen- utilizing Microbial Cultures. U.S. Patent US 8,557,563 B2, October 15th. 
Table 1: Performance parameters of digester groups.

\begin{tabular}{|c|ccc|}
\hline Group-> & G1 & G2 & G3 \\
\hline Digester Sets-> & A, B and C & D, E, F and G & H and I \\
\hline $\begin{array}{c}\text { Methane production rate } \\
\left(\mathrm{L}-\mathrm{CH}_{4} / \mathrm{L}_{\mathrm{R}} \text {-day at } 35^{\circ} \mathrm{C}, 1 \mathrm{~atm}\right)\end{array}$ & $0.77 \pm 0.12$ & $0.6 \pm 0.04$ & $0.34 \pm 0.02$ \\
\hline $\begin{array}{c}\text { SCOD removal } \\
(\%)\end{array}$ & $67 \pm 10$ & $55 \pm 4$ & $30 \pm 4$ \\
\hline $\mathrm{pH}$ & $7.2 \pm 0.06$ & $6.6 \pm 0.05$ & $6.3 \pm 0.0$ \\
\hline $\begin{array}{c}\text { Acetate } \\
\text { (g/L) }\end{array}$ & $2.4 \pm 0.6$ & $5.4 \pm 1$ & $7.3 \pm 2$ \\
\hline $\begin{array}{c}\text { Propionate } \\
(\mathrm{g} / \mathrm{L})\end{array}$ & $2.1 \pm 1$ & $4 \pm 1$ & $4.3 \pm 3$ \\
\hline
\end{tabular}




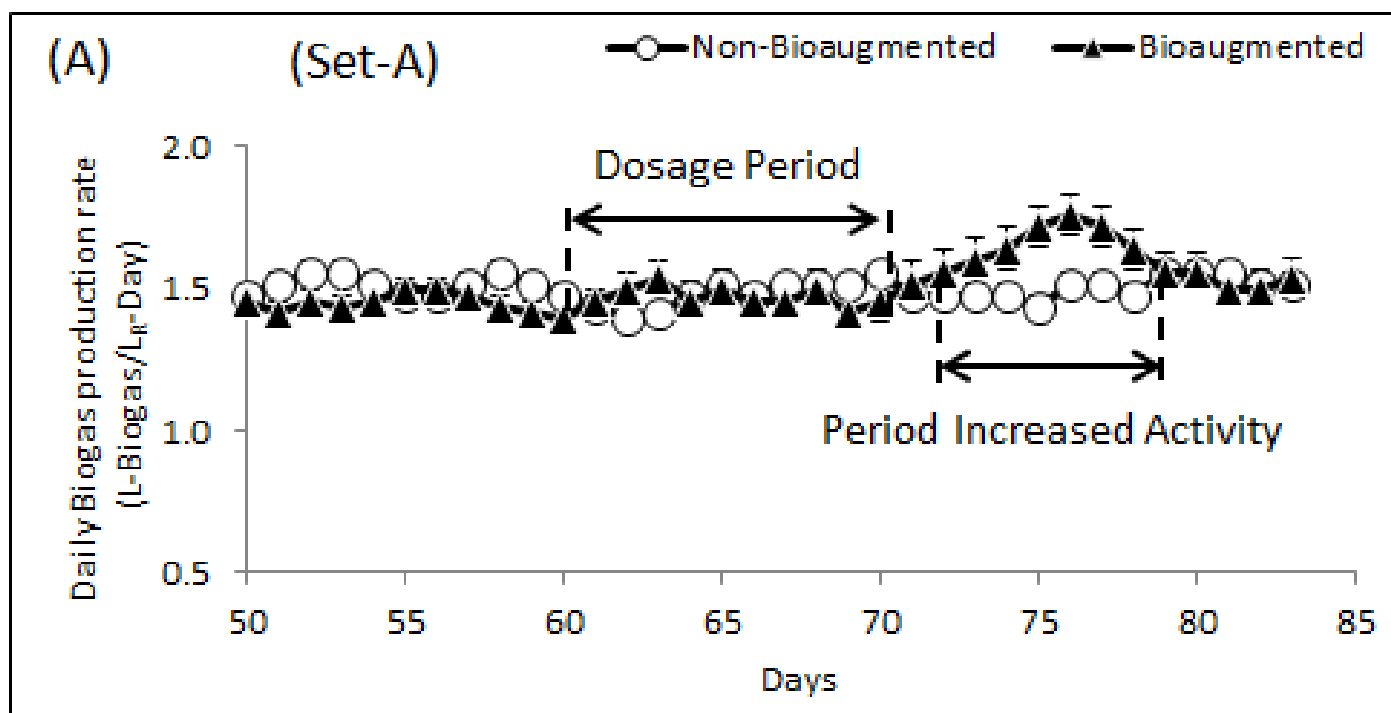

(B)

(Set-D)

-Non-Bioaugmented

$-\boldsymbol{L}$ Bioaugmented
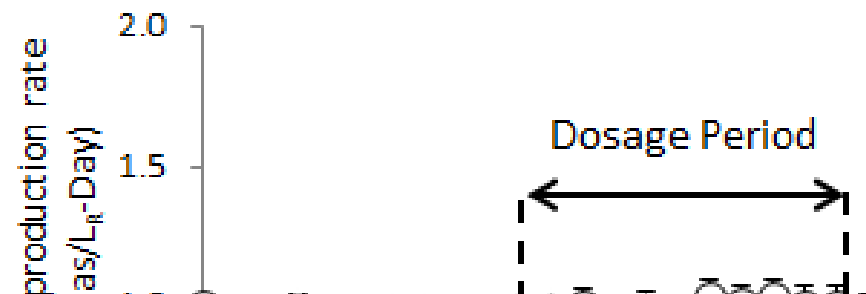

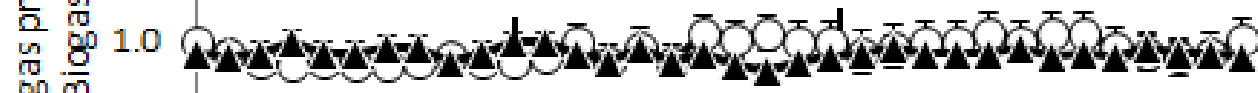

800

눌

$\frac{7}{\overline{0}}$

$\frac{\pi}{\pi} \quad 0.5$

5

$50 \quad 55 \quad 60$

65

70

$75 \quad 80$

Days

(C) (Set-H) $\quad \longrightarrow$ Non-Bioaugmented $\quad \longrightarrow$-Bioaugmented

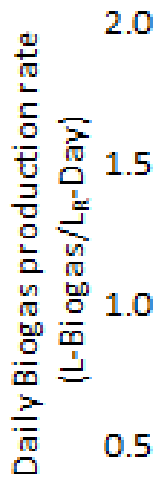

2.07

Dosage Period

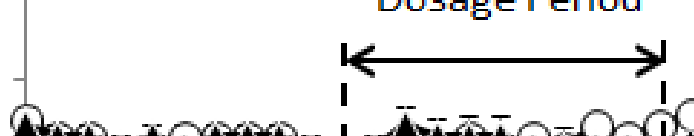

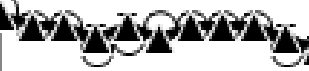

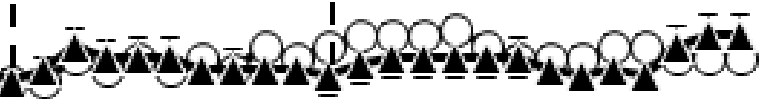

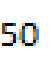

55

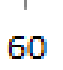

65

70

75

80 
Figure 1: Typical quasi steady state biogas production.

Daily biogas production rate observed from non-bioaugmented and bioaugmented digesters of (A) Set-A, (B) Set D and (C) Set H, respectively. The error bars represent standard deviation among triplicate digesters; some error bars are small and not visible. The dosage period represents the 10-day period during which inactivated and active enrichment cultures were added to non-bioaugmented and bioaugmented digesters, respectively. The Period of Increased Activity (period when bioaugmented digester methane production was statistically greater than that of non-bioaugmented digesters $(\mathrm{p}$ value $<0.05, \mathrm{n}=3)$ ). PIA was not observed for Set-D (B) and Set-H (C) digester systems. 

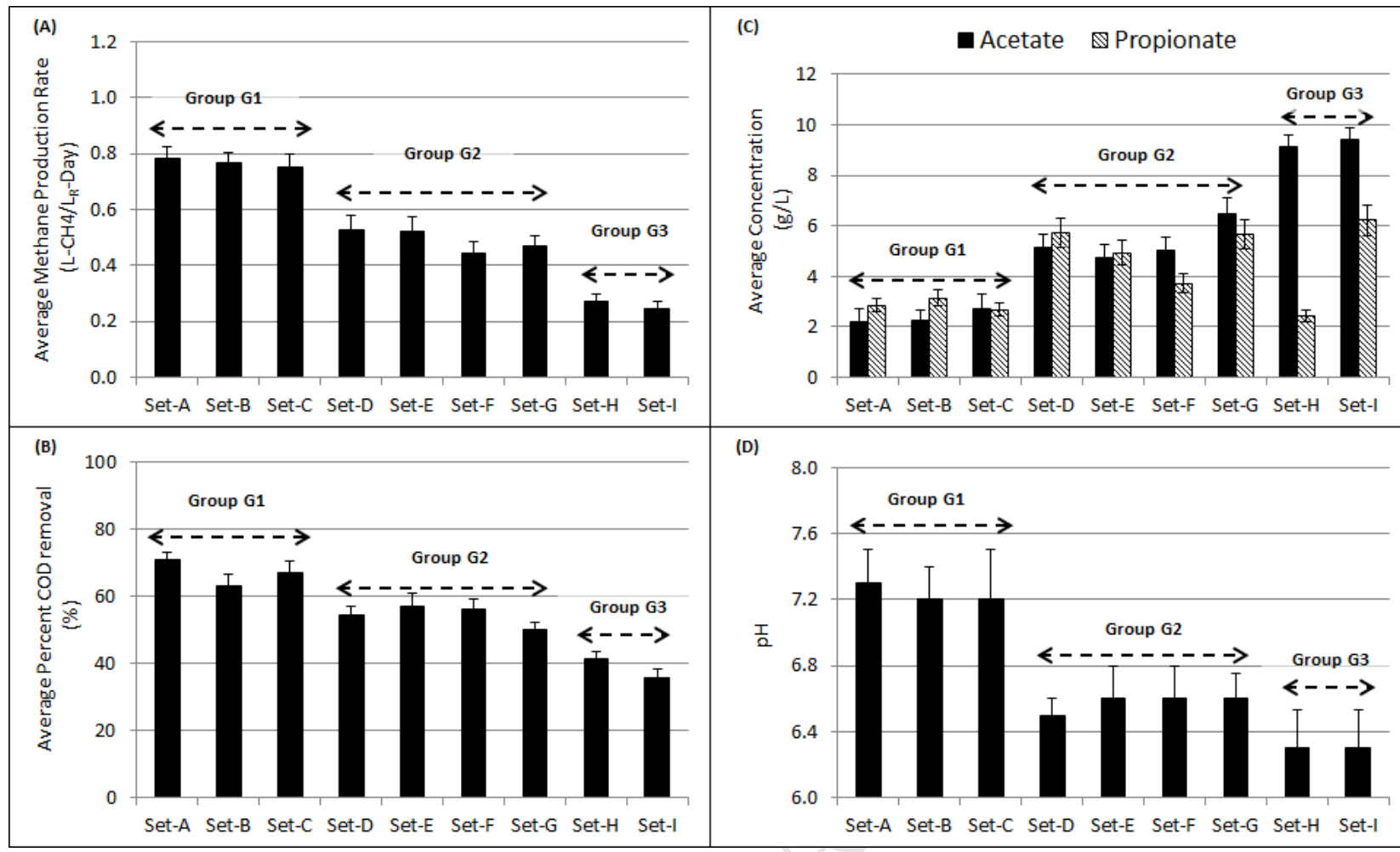

(D)

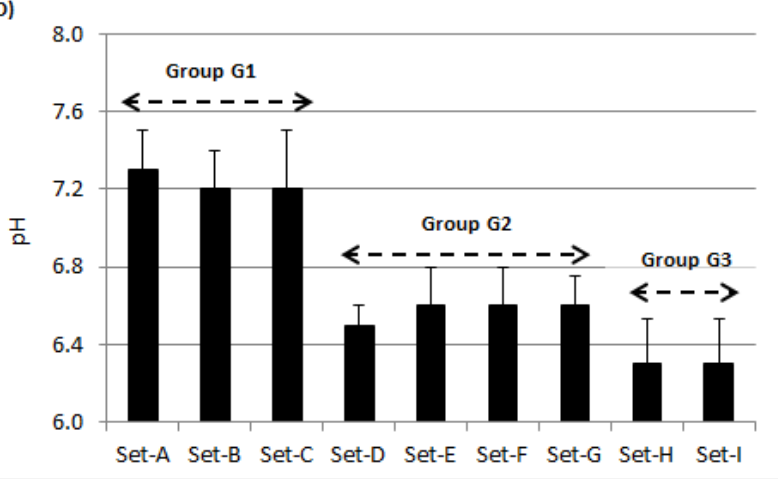

Figure 2: Digester group functional parameters.

(A) Average methane production rate $\left(\mathrm{L}_{-} \mathrm{CH}_{4} / \mathrm{L}_{\mathrm{R}}\right.$-day), (B) average percent COD removal, (C) average effluent acetate and propionate concentration, (D) and average effluent $\mathrm{pH}$. Error bars represent standard deviation among triplicates. Based on average functional performance, the nine digester sets were divided into three statistically distinct groups $(\mathrm{p}<0.05, \mathrm{n}=3)$ : digester groups G1 (Sets A, B and C), G2 (Sets D, E, F and G) and G3 (Sets H and I). 


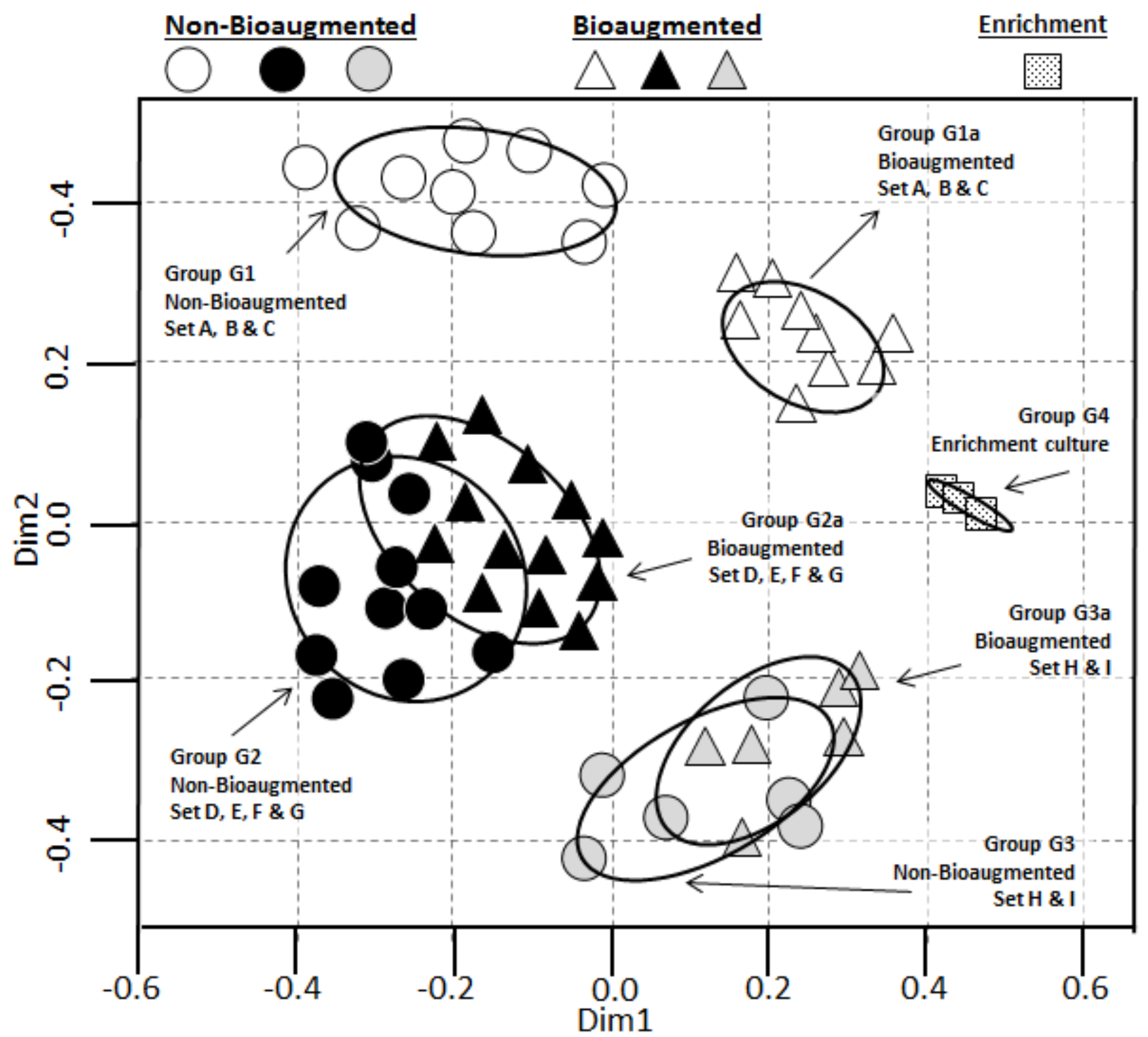

Figure 3: Archaeal sequence nMDS plot.

Non-bioaugmented digesters cluster 1, G1 $(\odot)$; non-bioaugmented digesters cluster 2, G2 $(\bullet)$; non-bioaugmented digesters cluster 3, G3 $(\bigcirc)$; bioaugmented digesters cluster 1 , G1a $(\triangle)$; bioaugmented digesters cluster 2, G2a $(\mathbf{\Lambda})$; bioaugmented digesters cluster 3, G3a $(\triangle)$; and enrichment culture G4 (図). The ellipses represent $95 \%$ confidence interval for each cluster. Eight archaeal OTU's, identified based on 97\% similarity and representing $>99 \%$ of the total archaeal sequences in all digesters, including the enrichment culture, were employed for nMDS analysis. 


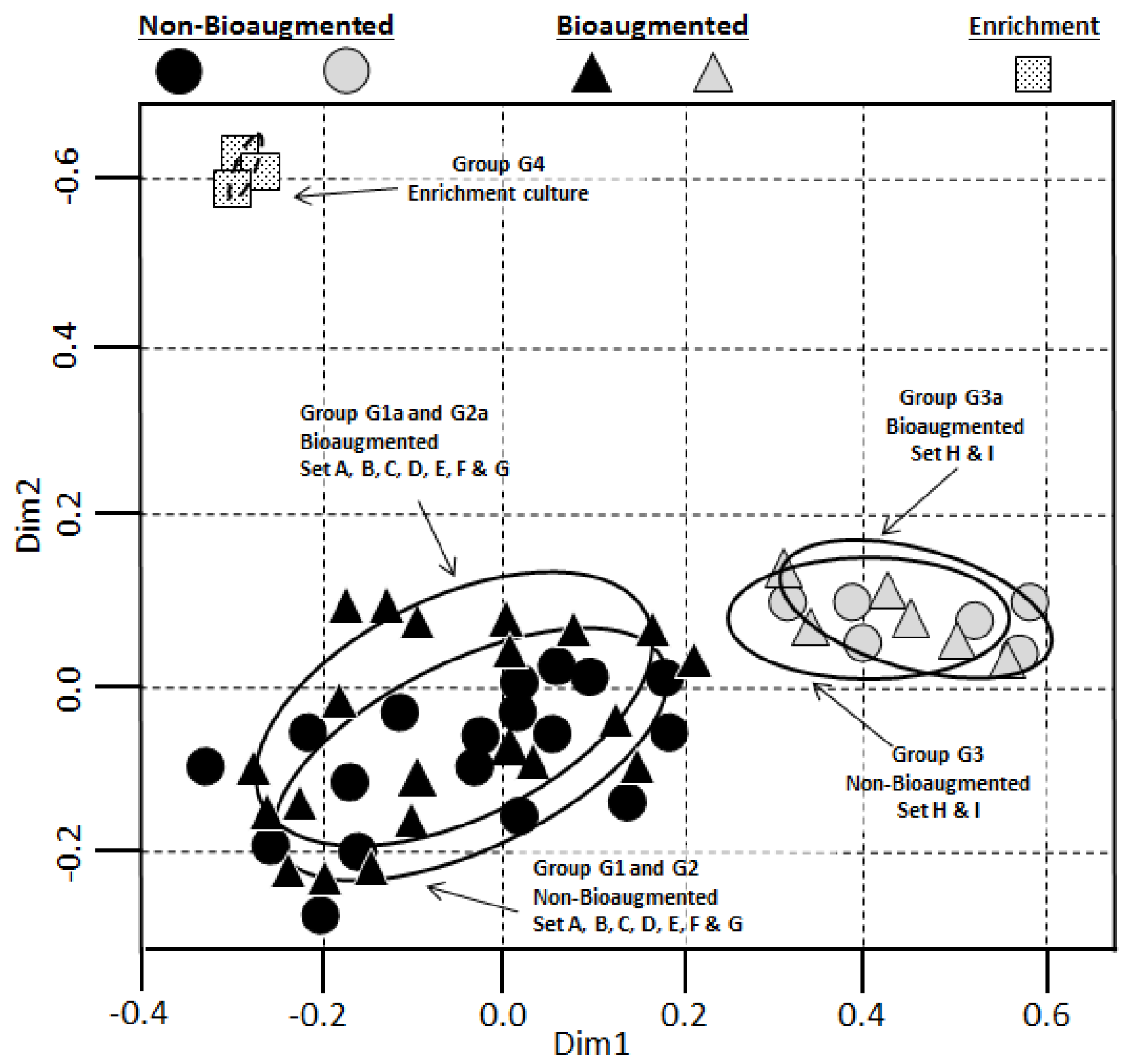

Figure 4: Bacterial sequence nMDS plot.

Non-bioaugmented digesters cluster 1, G1 and G2 $(\bullet)$; non-bioaugmented digesters cluster 2, G3 (O); enrichment culture G4 (图); bioaugmented digesters cluster 1, G1a and G2a $(\mathbf{\Delta})$; and bioaugmented digester cluster 2, G3a $(\triangle)$. The ellipses represent $95 \%$ confidence interval for each cluster. The 29 OTUs detected in all digesters with the highest relative abundance, including the enrichment culture, were employed for nMDS analysis. 


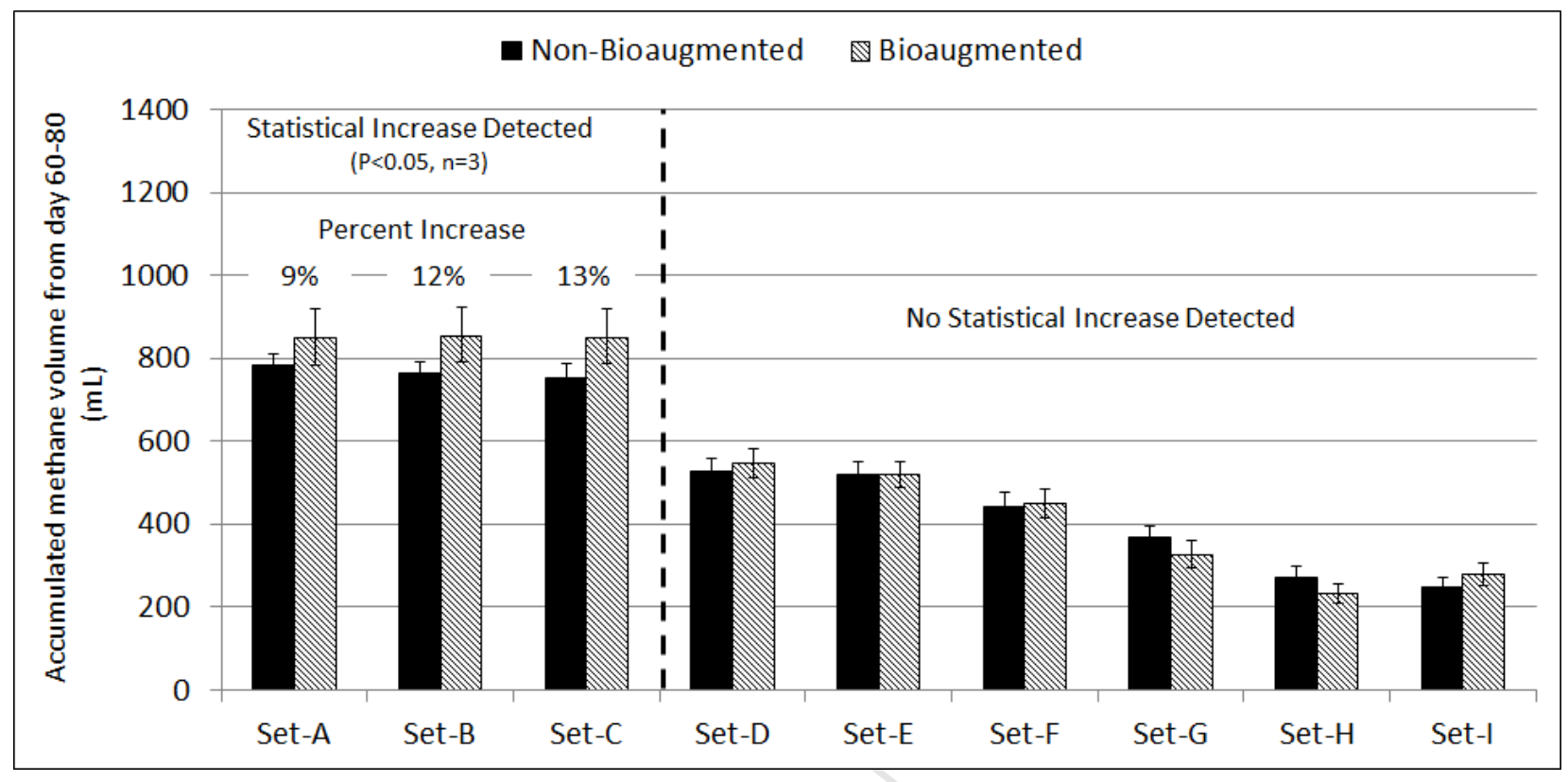

Figure 5: Cumulative $\mathrm{CH}_{4}$ produced between day 60-80.

Error bars represent standard deviation among triplicates. Bioaugmented digesters of Sets $\mathrm{A}, \mathrm{B}$ and $\mathrm{C}$ showed statistically higher cumulative $\mathrm{CH}_{4}$ production $(\mathrm{p}<0.05, \mathrm{n}=3)$. 


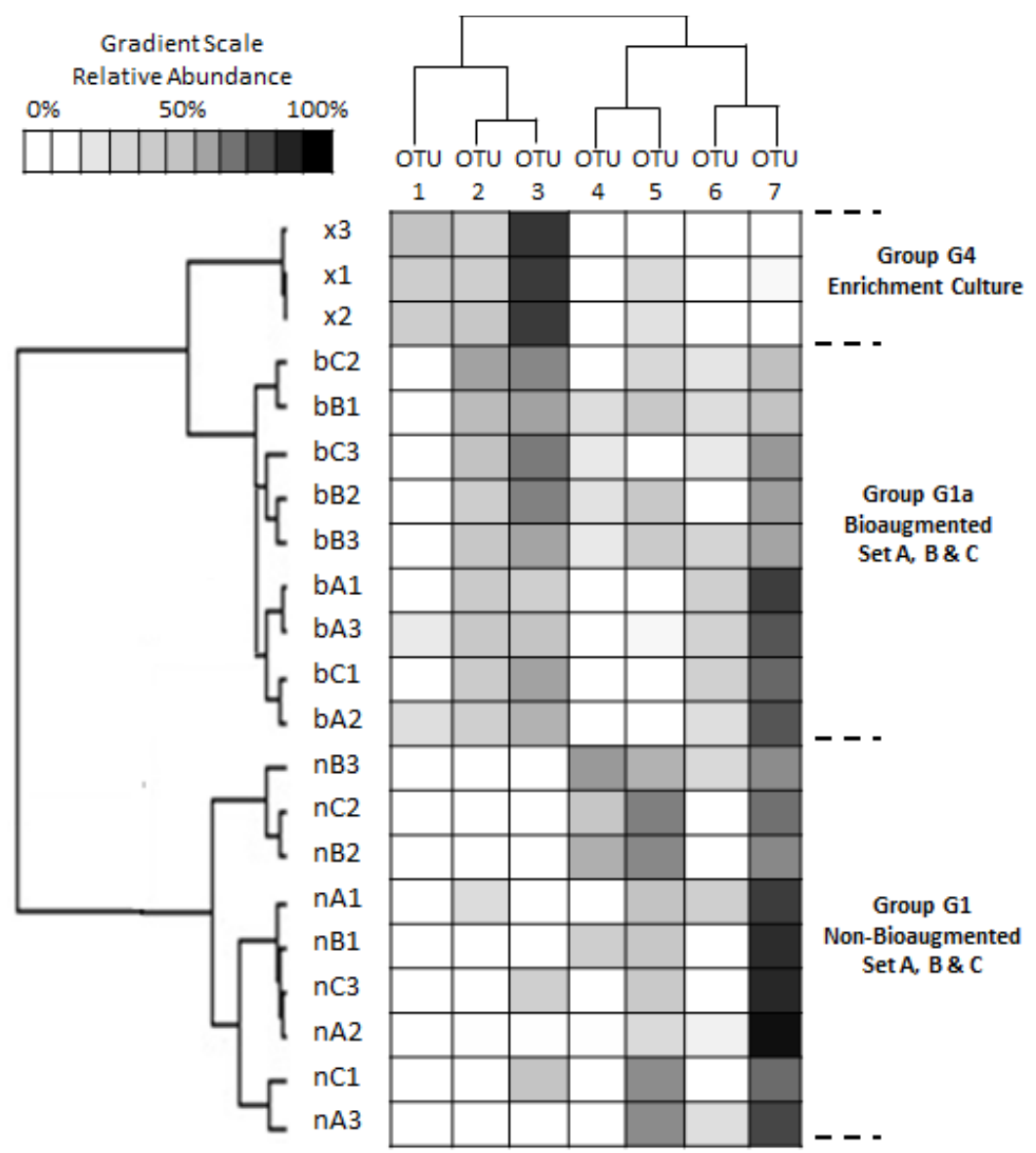

\begin{tabular}{|c|c|c|c|c|}
\hline OTU & Class & Order & Family & Genus \\
\hline 1 & Thermoplasmata & WCHA1-57 & unclassified & unclassified \\
\hline 2 & Methanomicrobia & Methanomicrobiales & Methanospirillaceae & Methanospirillum \\
\hline 3 & Methanomicrobia & Methanosarcinales & Methanosaetaceae & Methanofollis \\
\hline 4 & Methanomicrobia & Methanomicrobiales & Methanomicrobiaceae & Methanobacterium \\
\hline 5 & Methanobacteria & Methanobacteriales & Methanobacteriaceae & Methanosarcina \\
\hline 6 & Thermoplasmata & Thermoplasmatales & Thermoplasmatales Incertae Sedis & Candidatus Methanomethylophilus \\
\hline 7 & Methanomicrobia & Methanosarcinales & Methanosarcinaceae & \\
\hline
\end{tabular}

Figure 6: Dual hierarchal clustering of the top seven archaeal OTUs observed in the enrichment culture and G1 digesters.

These seven OTU's, based on $97 \%$ similarity, represent $>99 \%$ of the total archaeal abundance in the enrichment culture and G1 digesters. The gradient scale ranges from 0 to $100 \%$ relative abundance. Sample names x1, x2 and x3 represent the enrichment culture. The sample names for digesters are denoted as follows: for example "nB1" and bB1 - the prefix " $n$ " and " $b$ " represents "non-bioaugmented" and "bioaugmented", respectively, the middle letter "B" represents Set-B and the suffix "1" represent the replicate number. The enrichment culture is dominated by Methanosaeta(OTU 3), Methanospirillum (OTU 2) and WCHA1-57 (OTU 1). The non-bioaugmented digesters are dominated by Methanosarcina (OTU 7), followed by Methanobacterium (OTU 5). The bioaugmented digester of Set-A, B and C showed a significant abundance of Methanosaeta(OTU 3) and Methanospirillum (OTU 2) as compared to the nonbioaugmented digesters. 


\section{Highlights}

- Digesters with similar functional performance have similar methanogenic community structure and vice versa

- Bioaugmentation can improve methane production by shifting the digester's methanogenic community structure

- Washout of microorganisms, low $\mathrm{pH}$ and high acid concentrations may decrease the effectiveness of bioaugmentation 